\title{
Visual and optical performance of diffractive multifocal intraocular lenses with different haptic designs: 6 month follow-up
}

This article was published in the following Dove Press journal:

Clinical Ophthalmology

14 May 2014

Number of times this article has been viewed

\author{
Mengmeng Wang ${ }^{1, *}$ \\ Christine Carole C Corpuz' \\ Megumi Fujiwara' \\ Minoru Tomital,2,* \\ 'Shinagawa LASIK Center, Tokyo, \\ Japan; '2Department of Ophthalmology, \\ Wenzhou Medical College, Wenzhou, \\ People's Republic of China \\ *These authors contributed equally \\ to this work
}

Purpose: To evaluate and compare the visual acuity outcomes and optical performances of eyes implanted with two diffractive multifocal intraocular lens (IOL) models with either a plate haptic design or a modified-C design.

Methods: This retrospective study comprised cataract patients who were implanted with either a plate haptic multifocal IOL model (Acriva ${ }^{\text {UD }}$ Reviol BB MFM 611 [VSY Biotechnology, Amsterdam, the Netherlands], group 1) or a modified-C haptic multifocal IOL model (Acriva ${ }^{\mathrm{UD}}$ Reviol BB MF 613 [VSY Biotechnology, Amsterdam, the Netherlands], group 2) between June 2012 and May 2013. The 6 month postoperative visual acuity, refraction, defocus curve, contrast sensitivity, and wave-front aberration were evaluated and compared between these eyes, using different IOL models.

Results: One hundred fifty-eight eyes of 107 patients were included in this study. Significant improvement in visual acuities and refraction was found in both groups after cataract surgery $(P<0.01)$. The visual acuity and contrast sensitivity were statistically better in group 1 than in group $2(P<0.01)$. No statistically significant difference in the corneal higher-order aberrations was found between the two groups $(P>0.05)$. However, the ocular higher-order aberrations in group 2 were significantly greater than in group $1(P<0.05)$.

Conclusion: At 6 months postoperatively, both Acriva ${ }^{\mathrm{UD}}$ Reviol BB MFM 611 IOL and Acriva $^{\text {UD }}$ Reviol BB MF 613 IOL achieved excellent visual and refractive outcomes. The multifocal IOL model with plate haptic design resulted in better optical performances than that with the modified-C haptic design.

Keywords: Acriva ${ }^{U D}$, VSY, plate haptic, modified-C haptic, multifocal intraocular lens, cataract surgery

\section{Introduction}

Multifocal intraocular lens (IOL) implantation, introduced more than 20 years ago, is a popular procedure that achieves good visual acuity for both distance and near vision. ${ }^{1,2}$ Generally speaking, there are 3 types of multifocal IOLs: refractive, diffractive, and a combination of diffractive and refractive. ${ }^{3,4}$ Multifocal IOLs with a diffractive optic design have been proven to provide a significantly better near vision and reading performance than refractive multifocal IOLs and monofocal IOLs. ${ }^{5}$ With the addition of $\mathrm{a}+3.75 \mathrm{D}$ near power, good intermediate distance visions from diffractive multifocal IOL models were also proven in previous studies. ${ }^{6,7}$ In this study, the visual and optical performances were evaluated and compared between two new-generation multifocal IOL models, both with a near addition power of $+3.75 \mathrm{D}$ but with different haptic designs.
Correspondence: Minoru Tomita Shinagawa LASIK Center, ITOCiA I4F, 2-7-I Yurakucho, Chiyoda-ku, Tokyo 100-0006, Japan $\mathrm{Tel}+81352218137$

Fax +81352213138

Email tomita@shinagawa-lasik.com 


\section{Patients and methods \\ Study design}

This retrospective, single-center study comprised cataract patients who underwent cataract surgery with diffractive multifocal IOL implantation from June 2012 to May 2013 at the Shinagawa LASIK Center, Tokyo, Japan. The inclusion criteria were patients with incipient or moderate cataracts resulting in a significant reduction of the visual quality. The exclusion criteria were patients with active ocular diseases or significant amounts of corneal aberrations observed on the topography map. Eyes with serious postoperative complications (such as posterior-capsular opacity [PCO] and obvious capsule contraction) were likewise excluded to achieve the accurate outcomes of visual and optical performance. These included eyes were randomly divided into two groups and implanted with multifocal IOLs: Acriva $^{\mathrm{UD}}$ Reviol BB MFM 611 (VSY Biotechnology, Amsterdam, the Netherlands) for group 1 and Acriva ${ }^{\mathrm{UD}}$ Reviol BB MF 613 (VSY Biotechnology, Amsterdam, the Netherlands) for group 2. All patients read and signed the informed consent forms, which explained the surgical procedure, possible risks, and patient rights. The study was carried out with approval from the Institutional Review Board (Matsumoto Clinic, Tokyo, Japan), and all patients consented.

\section{Preoperative examinations}

Preoperative examinations included uncorrected distance visual acuity (UDVA), corrected distance visual acuity (CDVA), manifest refraction spherical equivalent (MRSE), uncorrected near visual acuity (UNVA), corrected near visual acuity (CNVA), slit lamp biomicroscopy, funduscopy, intraocular pressure (Computerized Tonometer ${ }^{\mathrm{TM}}$; Topcon Corp, Tokyo, Japan), tomography (Pentacam ${ }^{\mathrm{TM}}$; Oculus Optikgeräte GmbH, Wetzlar, Germany), and corneal endothelial cell count (Noncon Robo ${ }^{\mathrm{TM}}$ FA3609; Konan Medical Inc, Hyogo, Japan). ${ }^{8}$ IOLMaster ${ }^{\mathrm{TM}}$ (Carl Zeiss Meditec, Jena, Germany) was used for the biometry and power calculation of the multifocal IOLs. The visual and refractive outcomes of all patients were measured by an independent optometrist. All examiners were masked to the IOL models implanted into these patients.

\section{Multifocal IOLs}

The diffractive multifocal IOL with a plate haptic design used in this study was the Acriva ${ }^{\mathrm{UD}}$ Reviol BB MFM $611 \mathrm{IOL}$ (Figure 1, left). According to the manufacturer, this diffractive multifocal IOL has $3.75 \mathrm{D}$ of addition power and ultradefinition aspheric optic design. It can provide high-quality far, middle, and near vision. It has been verified to have smooth ridges at the diffractive ring transitions to increase retinal image quality. It also has a 360 degree continuous square optic and haptic edge to reduce the $\mathrm{PCO}$ formation. ${ }^{6}$ The Acriva $^{\mathrm{UD}}$ Reviol BB MF 613 IOL has the same ultradefinition aspheric optic design as the Acriva ${ }^{\mathrm{UD}}$ Reviol BB MFM 611 IOL, but with a modified-C haptic design (Figure 1, right). The $C$ haptic size is $13.00 \mathrm{~mm}$, with a $0^{\circ}$ haptic angle. Both multifocal IOL models are made of hydrophilic acrylic with a hydrophobic surface. Sixty percent of the intraocular light was allotted for far focus, and $40 \%$ for near.

\section{Surgical technique}

All surgeries were performed by the same surgeon (MT), using femtosecond laser-assisted phacoemulsification. ${ }^{9}$ After topical anesthesia and adequate dilation, femtosecond laser (Catalys ${ }^{\mathrm{TM}}$ Precision Laser System; Optimedica Corp, Sunnyvale, CA, USA) was used for the continuous curvilinear capsulorrhexis (CCC) and lens fragmentation of all cataracts. The incision was created on the steepest corneal meridian.

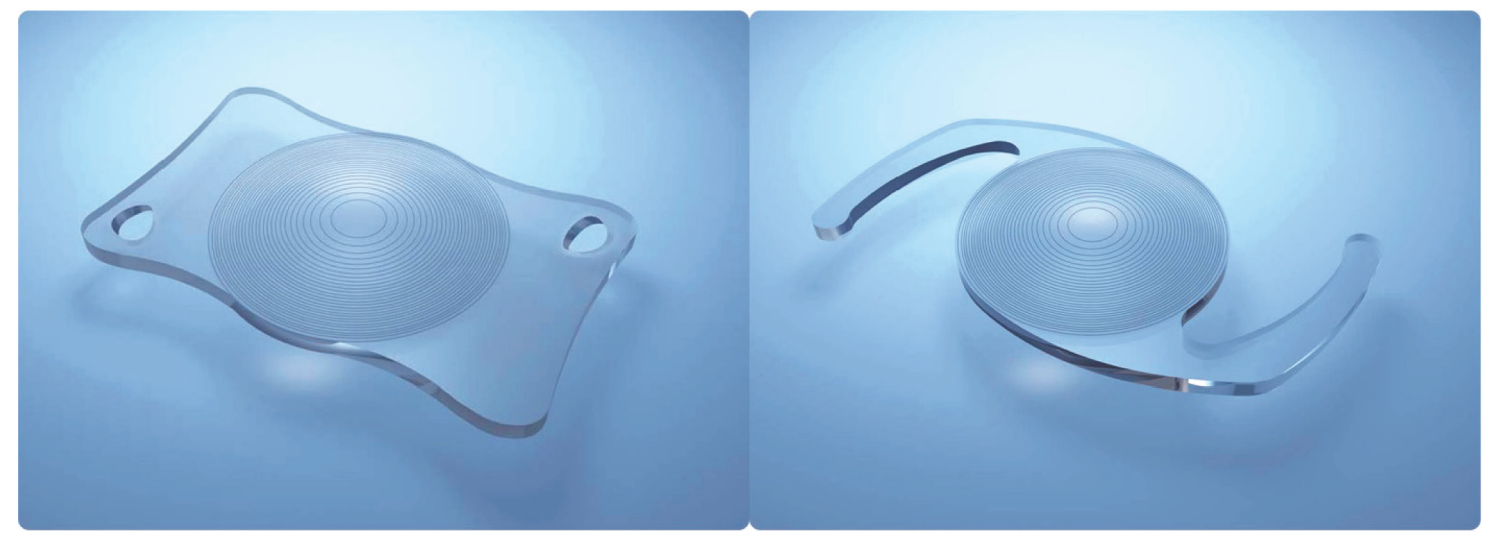

Figure I A general view of the Acriva ${ }^{\mathrm{UD}}$ Reviol BB MFM 6 I I lens (left) and the Acriva ${ }^{\mathrm{UD}}$ Reviol BB MF 613 intraocular lens (right).

Notes: Acriva ${ }^{\mathrm{UD}}$ Reviol BB MFM $61 \mathrm{I}$ lens (VSY Biotechnology, Amsterdam, the Netherlands); Acriva ${ }^{\mathrm{UD}}$ Reviol BB MF 613 intraocular lens (VSY Biotechnology, Amsterdam, the Netherlands). 
Viscoelastic material (Provisc ${ }^{\mathrm{TM}}$; Alcon Corp, Fort Worth, TX, USA) was injected, and the cut capsule was removed. Phacoemulsification was performed using the Infiniti ${ }^{\circledR}$ Vision System (Alcon Corp). The foldable multifocal IOL was inserted and rotated into the intact capsular bag. The viscoelastic material was completely removed by irrigation and aspiration. All incisions were left sutureless.

\section{Postoperative treatments}

In all cases, the postoperative medications were given as follows: a 500 mg oral levofloxacin (Cravit ${ }^{\mathrm{TM}}$; Daiichi Sankyo, Tokyo, Japan) once a day for 3 days and $0.1 \%$ diclofenac sodium eye drops (Diclofenac Ophthalmic Solution 0.1\%; Nitto Medic, Toyama, Japan), $0.1 \%$ dexamethasone metasulfobenzoate sodium (D.E. $\mathrm{X}^{\mathrm{TM}}$; Nitto Medic), and $0.5 \%$ moxifloxacin hydrochloride (Vegamox ${ }^{\mathrm{TM}}$; Alcon Corp) five times a day for 1 week. After 1 week, diclofenac use was reduced to 4 times a day for 1 month, and the latter drugs were shifted to topical $0.1 \%$ fluorometholone ophthalmic suspension (Fluorometholone Ophthalmic Suspension 0.1\% T; Nitto Medic) and $0.3 \%$ ofloxin ophthalmic solution (Ofloxin Ophthalmic Solution 0.3\%; Nitto Medic), prescribed four times a day up to 1 month, after which their use was discontinued.

\section{Postoperative examinations}

Postoperatively, visual and refractive examinations were routinely performed during the 6 month follow-up, following the same investigational protocol. At 6 months postoperatively, a defocus curve was obtained by spectacle defocus from $+2.00 \mathrm{D}$ to $-5.00 \mathrm{D}$ in $0.50 \mathrm{D}$ steps from the patient's manifest refraction. The direct comparison method was used to compare the visual acuities between two groups at each defocus level. ${ }^{10}$ Functional acuity contrast was tested using the Takagi ${ }^{\mathrm{TM}}$ Contrast Glare Tester CGT-1000 (Takagi Seiko Co Ltd, Nagano-Ken, Japan) for different ambient light conditions (with and without glare) at luminance levels of 21 candelas $(\mathrm{cd}) / \mathrm{m}^{2}$ (day testing) and $11 \mathrm{~cd} / \mathrm{m}^{2}$ (night testing). ${ }^{11}$ Wave-front aberration was tested using the Wave-Front Analyzer ${ }^{\mathrm{TM}} \mathrm{KR}-1 \mathrm{~W}$ (Topcon Corp) 6 months postoperatively.

\section{Statistical analysis}

Statistical analysis was performed with JMP ${ }^{\mathrm{TM}} 9$ statistical package (SAS Institute, Inc, Cary, NC, USA) software. Descriptive statistical results were presented as mean and standard deviation. To compare the differences between the two groups, one-way analysis of variance and KruskalWallis tests were used for parametric and nonparametric tests, respectively. Results with $P<0.05$ were considered statistically significant.

\section{Results}

A total of 158 eyes of 107 patients were included in this study. The mean age of all patients was $60.90 \pm 5.72$ years (range, 45-76 years). Group 1 consisted of 89 eyes of 62 patients aged between 47 and 76 years (mean age, $60.74 \pm 5.92$ years); group 2 included 69 eyes of 45 patients aged between 45 and 73 years (mean age, 61.13 \pm 5.46 years). Table 1 shows the preoperative and 6 month postoperative outcomes in visual and refractive parameters of the two groups. No statistically significant differences in terms of age, visual acuity, and refractive parameters were found between the two groups preoperatively $(P>0.05)$. At 6 months postoperatively, significant improvements in UDVA, CDVA, MRSE, UNVA, and CNVA were found in both groups $(P<0.05)$. Comparing the two groups, plate haptic multifocal IOLs (group 1) provided statistically better outcomes in UDVA, CDVA, and CNVA $(P<0.05)$.

Figure 2 summarizes the cumulative percentage of the UDVA in each group 6 months postoperatively. Figure 3 shows the cumulative percentage of the UNVA. Eighty-five percent of the eyes in group 1 and $74 \%$ of the eyes in group 2 achieved a UDVA of 20/20 (0.00 logMAR) or better. For UNVA, 69\% of the eyes in group 1 and 54\% of the eyes in group 2 achieved Jaeger 3 ( $0.18 \log$ MAR) or better at the end of the follow-up.

Figure 4 shows the contrast sensitivities of two groups 6 months postoperatively. At any level of the target size (visual angle, degree [d]), the mean values of contrast sensitivity

Table I Preoperative and 6 month postoperative conditions of the two groups

\begin{tabular}{llll}
\hline Parameter & Group I & Group 2 & $\boldsymbol{P}$ \\
\hline Pre & & & \\
UDVA, LogMAR & $0.71 \pm 0.57$ & $0.75 \pm 0.54$ & 0.66 \\
CDVA, LogMAR & $-0.08 \pm 0.1 \mathrm{I}$ & $-0.05 \pm 0.15$ & 0.42 \\
MRSE, D & $-2.89 \pm 5.94$ & $-2.20 \pm 5.64$ & 0.27 \\
UNVA, LogMAR & $0.71 \pm 0.37$ & $0.80 \pm 0.39$ & 0.09 \\
CNVA, LogMAR & $0.02 \pm 0.07$ & $0.04 \pm 0.11$ & 0.63 \\
Add, D & $2.21 \pm 0.66$ & $2.44 \pm 0.50$ & $0.03^{*}$ \\
6 m & & & \\
UDVA, LogMAR & $-0.05 \pm 0.13$ & $0.02 \pm 0.14$ & $0.00^{*}$ \\
CDVA, LogMAR & $-0.16 \pm 0.05$ & $-0.13 \pm 0.08$ & $0.01 *$ \\
MRSE, D & $0.69 \pm 0.49$ & $0.75 \pm 0.49$ & 0.15 \\
UNVA, LogMAR & $0.15 \pm 0.14$ & $0.20 \pm 0.17$ & 0.06 \\
CNVA, LogMAR & $0.01 \pm 0.02$ & $0.02 \pm 0.07$ & $0.02 *$ \\
Add, D & $0.14 \pm 0.36$ & $0.25 \pm 0.64$ & 0.79 \\
\hline
\end{tabular}

Note: Statistically significant at the level $* P<0.05$.

Abbreviations: Pre, preoperative conditions; UDVA, uncorrected distance visua acuity; CDVA, corrected distance visual acuity; MRSE, manifest refraction spherical equivalent; D, diopters; UNVA, uncorrected near visual acuity; CNVA, corrected near visual acuity; Add, near addition; $6 \mathrm{~m}$, postoperative conditions 6 months after cataract surgery. 


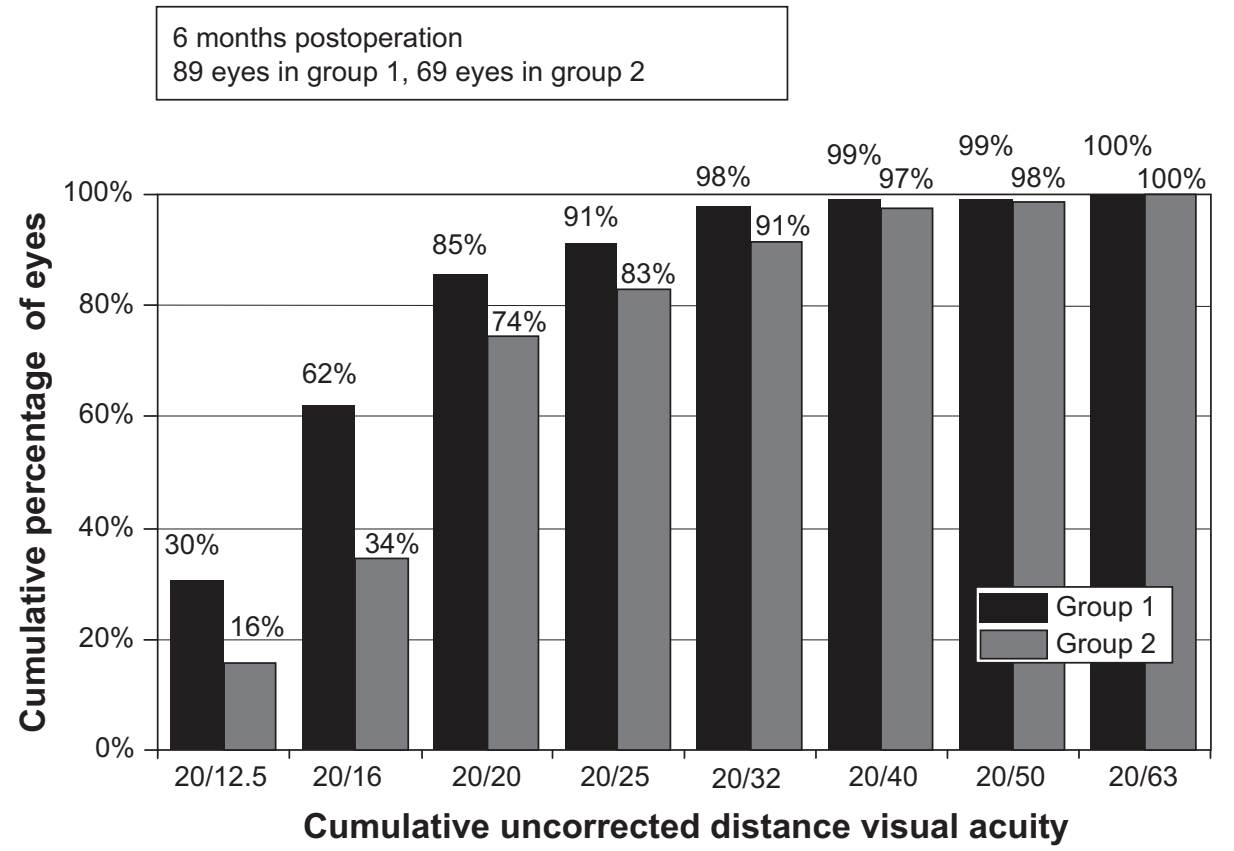

Figure 2 Cumulative uncorrected distance visual acuity of the eyes with the different intraocular lenses at 6 months postoperation.

Notes: Group I, eyes with Acriva ${ }^{\mathrm{DD}}$ Reviol BB MFM 611 intraocular lens. Group 2, eyes with Acriva ${ }^{\mathrm{UD}}$ Reviol BB MF 613 intraocular lens (VSY Biotechnology, Amsterdam, the Netherlands).

were higher in group 1 than in group 2. These differences between the two groups were statistically significant both under photopic $(6.3 \mathrm{~d}, P<0.0001 ; 4.0 \mathrm{~d}, P<0.0001 ; 2.5$ d, $P<0.0001 ; 1.6 \mathrm{~d}, P<0.0001 ; 1.0 \mathrm{~d}, P<0.0001 ; 0.7 \mathrm{~d}$, $P=0.01)$ and mesopic $(6.3 \mathrm{~d}, P<0.0001 ; 4.0 \mathrm{~d}, P<0.0001$; $2.5 \mathrm{~d}, P<0.0001 ; 1.6 \mathrm{~d}, P<0.0001 ; 1.0 \mathrm{~d}, P<0.0001 ; 0.7 \mathrm{~d}$, $P<0.0001)$ conditions.
With a slight visual decline in the intermediate range, the defocus curves in Figure 5 show good functional capacities for distant and near vision of eyes with either of the two multifocal IOL models. Statistically significant differences were found between the two groups when the defocus addition was $-1.00 \mathrm{D}$ $(P=0.03),-0.50 \mathrm{D}(P=0.00)$, and $0.00 \mathrm{D}(P=0.02)$. The highest near-visual peaks were $-0.07 \pm 0.10 \log$ MAR for the Acriva ${ }^{\text {UD }}$

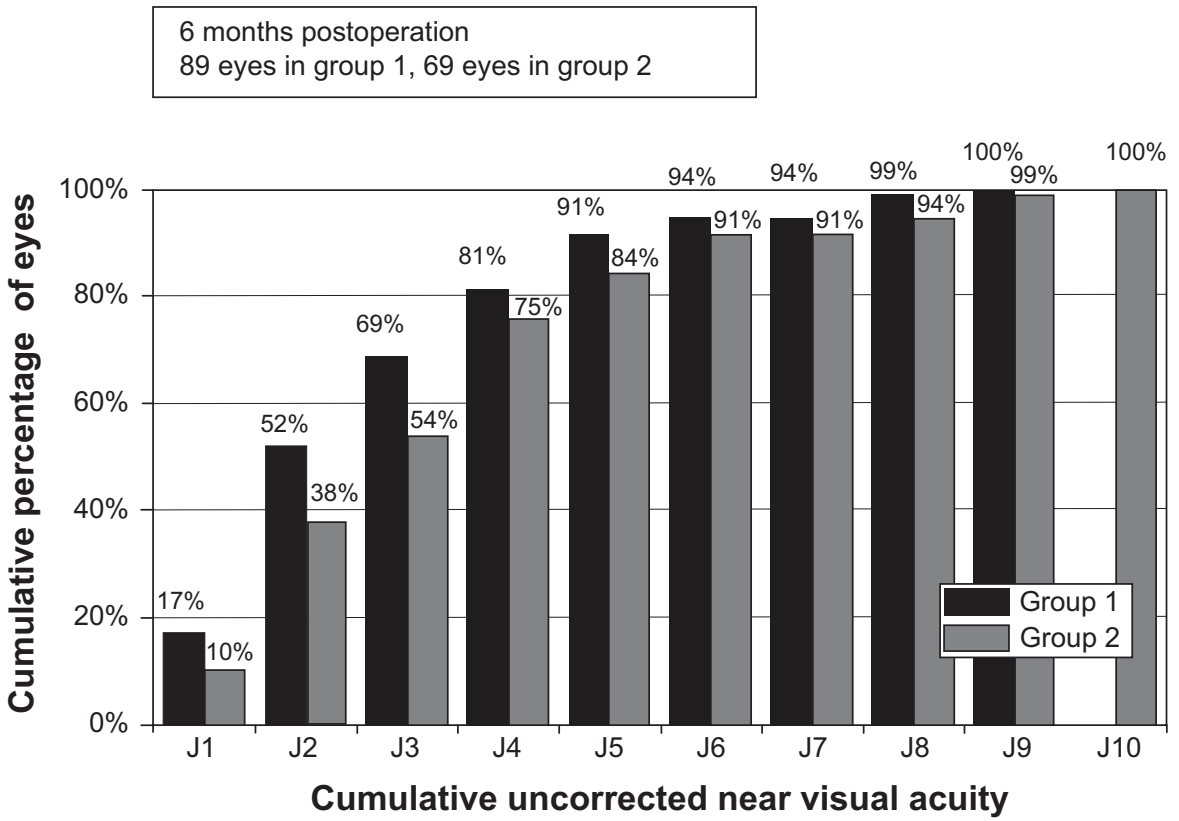

Figure 3 Cumulative uncorrected near visual acuity of the eyes with different intraocular lenses at 6 months postoperation.

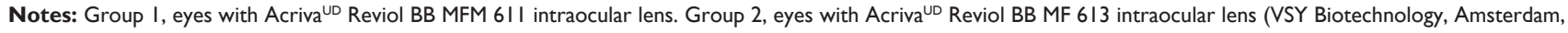
the Netherlands). 
Light on

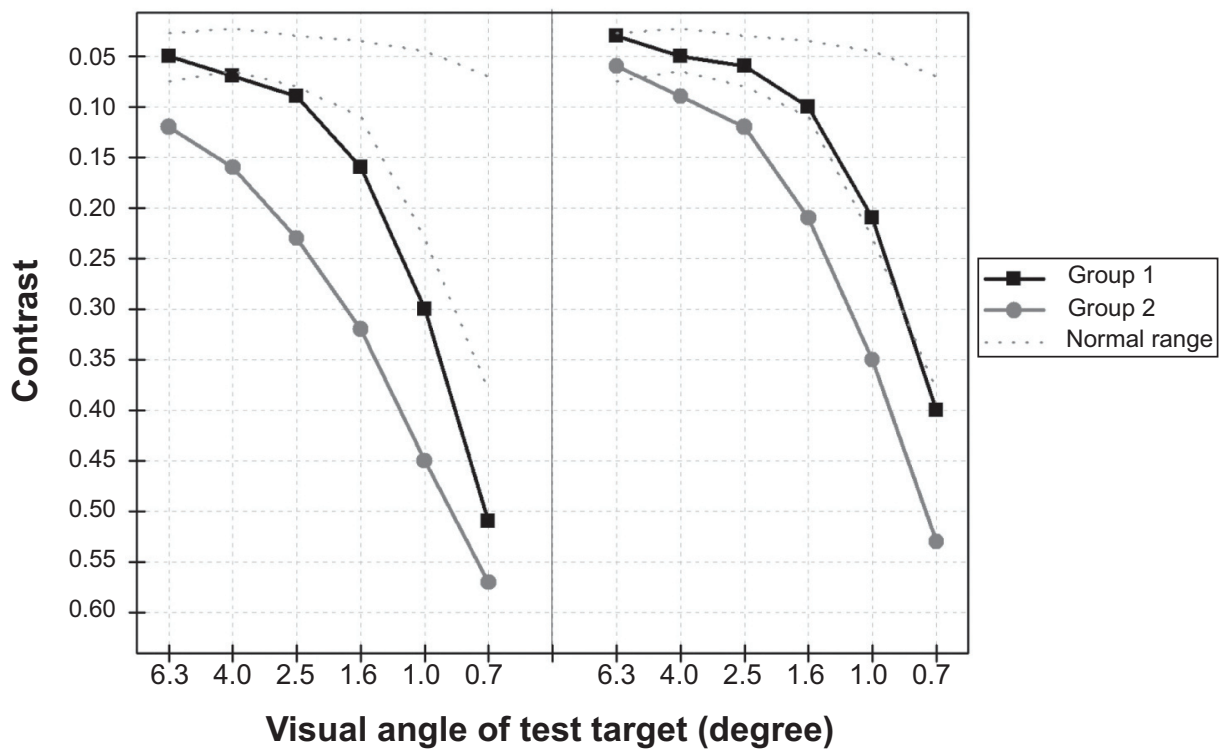

Figure 4 Contrast sensitivity under photopic (light on, 21 candelas $/ \mathrm{m}^{2}$ ) and mesopic (light off, II candelas $/ \mathrm{m}^{2}$ ) conditions of eyes implanted with different multifocal intraocular lenses at 6 months postoperation.

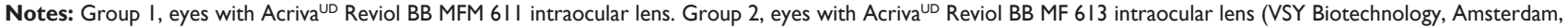
the Netherlands).

Reviol BB MFM 611 IOL and $-0.06 \pm 0.09 \log$ AAR for the Acriva $^{\mathrm{UD}}$ Reviol BB MF 613 IOL; both peaks were present at $33 \mathrm{~cm}(-3.00 \mathrm{D})$.

Table 2 summarizes the comparison of postoperative higher-order aberrations (HOAs) in the two groups. No statistically significant difference in corneal HOAs for either photopic vision ( $4 \mathrm{~mm}$ diameter) or scotopic vision (6 $\mathrm{mm}$ diameter) was found between two groups at the end of the follow-up $(P>0.05)$. However, the ocular HOAs in group 2 were significantly greater than in group $1(P<0.05)$.

\section{Discussion}

Both Acriva ${ }^{\mathrm{UD}}$ Reviol BB MFM 611 IOL and Acriva ${ }^{\mathrm{UD}}$ Reviol BB MF 613 IOL are new-generation diffractive multifocal

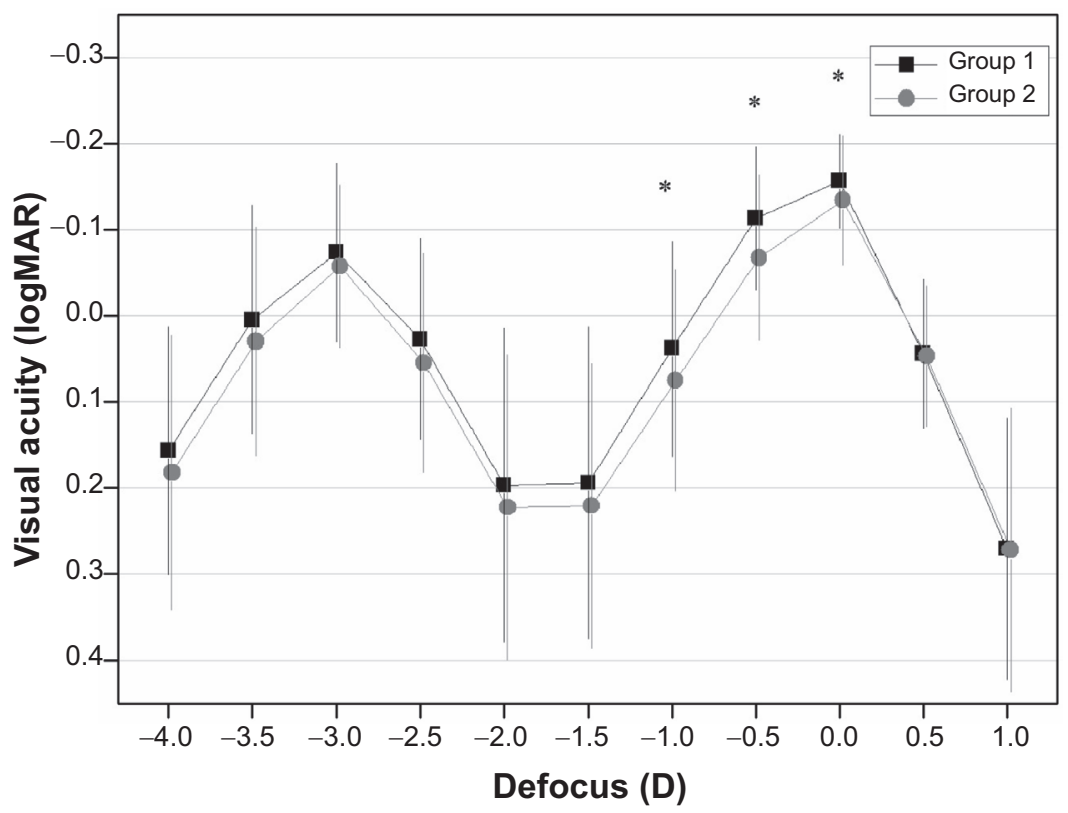

Figure $\mathbf{5}$ Visual acuity at the different levels of defocus for the two groups of lenses.

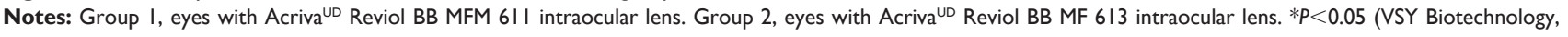
Amsterdam, the Netherlands). 
Table 2 Higher-order wavefront aberrations of the two multifocal intraocular lens groups at 6 months postoperation

\begin{tabular}{|c|c|c|c|c|c|c|}
\hline \multirow[t]{2}{*}{ Parameter } & \multicolumn{3}{|l|}{ Mire ring } & \multicolumn{3}{|c|}{ Hartmann shack } \\
\hline & Group I & Group 2 & $P$ & Group I & Group 2 & $P$ \\
\hline \multicolumn{7}{|l|}{ Photopic } \\
\hline S3 & $0.11 \pm 0.04$ & $0.11 \pm 0.04$ & 0.68 & $0.15 \pm 0.11$ & $0.23 \pm 0.23$ & $0.02^{*}$ \\
\hline S4 & $0.05 \pm 0.01$ & $0.04 \pm 0.01$ & 0.06 & $0.08 \pm 0.08$ & $0.15 \pm 0.14$ & $0.00 *$ \\
\hline Total & $0.13 \pm 0.04$ & $0.12 \pm 0.04$ & 0.47 & $0.17 \pm 0.12$ & $0.28 \pm 0.26$ & $0.00 *$ \\
\hline \multicolumn{7}{|l|}{ Scotopic } \\
\hline S3 & $0.37 \pm 0.15$ & $0.36 \pm 0.14$ & 0.96 & $0.45 \pm 0.23$ & $0.80 \pm 0.53$ & $0.03^{*}$ \\
\hline S4 & $0.26 \pm 0.07$ & $0.24 \pm 0.06$ & 0.24 & $0.30 \pm 0.11$ & $0.72 \pm 0.97$ & 0.25 \\
\hline S5 & $0.09 \pm 0.04$ & $0.09 \pm 0.04$ & 0.34 & $0.16 \pm 0.09$ & $0.50 \pm 0.58$ & 0.10 \\
\hline S6 & $0.04 \pm 0.02$ & $0.04 \pm 0.02$ & 0.81 & $0.13 \pm 0.11$ & $0.38 \pm 0.74$ & 0.57 \\
\hline $\mathrm{S} 3+5$ & $0.38 \pm 0.15$ & $0.37 \pm 0.13$ & 0.92 & $0.49 \pm 0.22$ & $0.97 \pm 0.75$ & $0.03^{*}$ \\
\hline S4+6 & $0.26 \pm 0.07$ & $0.25 \pm 0.06$ & 0.26 & $0.33 \pm 0.14$ & $0.83 \pm 1.21$ & 0.18 \\
\hline Total & $0.47 \pm 0.13$ & $0.46 \pm 0.11$ & 0.81 & $0.6 \mathrm{I} \pm 0.22$ & $1.33 \pm 1.37$ & 0.09 \\
\hline
\end{tabular}

Notes: Corneal and ocular wavefront aberrations were obtained using Mire ring Sensor (Wave-Front Analyzer KR-IW, Topcon Corporation, Tokyo, Japan) and HartmannShack Sensor (Wave-Front Analyzer KR-IW, Topcon Corporation), respectively. S3, S4, S5 and S6 are the RMS of the third-, fourth-, fifth- and sixth-order Zernike coefficients, respectively; $\mathrm{S} 3+5$, total coma aberration; $\mathrm{S4}+6$, total spherical aberration; Total, total higher-order aberration (S3+4+5+6). Group I, eyes with Acriva ${ }^{\mathrm{UD}}$ Reviol MFM 6 I I intraocular

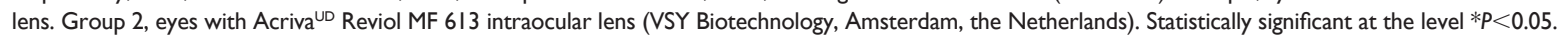

IOL models with a near addition of $+3.75 \mathrm{D}$ and a 360 degree continuous square edge. Previous study has proven that a clear Acriva $^{\mathrm{UD}}$ Reviol model with plate haptic design (Acriva ${ }^{\mathrm{UD}}$ Reviol MFM 611) provides excellent visual acuity and contrast sensitivity. ${ }^{6}$ Theoretically, both Acriva ${ }^{\mathrm{UD}}$ Reviol BB MF 613 and BB MFM 611 should have yielded the same visual and optical performances because they have the same optic design. However, many factors can actually affect the visual and optical outcomes of multifocal IOL implantations and can cause patient dissatisfaction, such as IOL decentration or tilt., ${ }^{3,12}$ Haptic deformation and flexion caused by anterior capsule contraction were thought to play major roles in these decentrations and tilts. ${ }^{13,14}$ The aim of the present study was to evaluate and compare the visual and optical performances of these two multifocal IOL models with different haptic designs.

Before the cataract surgery, no statistically significant differences were found in age, UDVA, CDVA, MRSE, UNVA, or CNVA between the two groups. At 6 months postoperatively, significant improvements in distance (8 lines increased in both groups) and near (7 lines increased in group 1, 8 lines in group 2) visual acuities were found, which confirmed the efficacy of the two multifocal IOL models.

Nevertheless, the plate haptic IOL model (Acriva ${ }^{\mathrm{UD}}$ Reviol BB MFM 611, group 1) appeared to yield better visual and optical performances than the $\mathrm{C}$ haptic IOL model (Acriva ${ }^{\mathrm{UD}}$ Reviol BB MF 613, group 2). Similar outcomes can be found in eyes implanted with some other monofocal and refractive multifocal IOL models. ${ }^{13-18}$ For example, the plate haptic IOL models of Lentis Mplus ${ }^{\mathrm{TM}}$ (Oculentis GmbH, Berlin, Germany) can provide better refractive predictability and optical quality than the $\mathrm{C}$ haptic IOL models. ${ }^{14}$
In the current study, because of the same optic design, the visual and optical differences between two diffractive multifocal IOL models might be caused by their different positional stabilities within the capsular bags. It was found that diffractive IOLs were much more sensitive to their own stability than monofocal and refractive multifocal IOLs. ${ }^{13}$ Even a small misalignment of the central concentric rings can lead diffractive multifocal IOLs to provide significantly reduced results. In the current study, the different stabilities between the two models would have been because of the following reasons: first, the haptic designs of these models should have been the major reason for their different stabilities. It has been found that three-piece $\mathrm{C}$ haptic IOLs had a greater tendency toward more decentration than one-piece IOLs; ${ }^{18}$ plate haptics provided greater stability for IOLs than the $\mathrm{C}$ haptics and cannot be easily affected by the IOL orientation. ${ }^{13,18,19}$ It was also proven that the IOL tilt and decentration were correlated with coma and total aberrations. ${ }^{20}$ Because our outcomes include both visual and optical performances, those eyes that could affect the visual and optical measurements (such as $\mathrm{PCO}$ and other serious postoperative complications) were excluded from both groups. This makes the IOL decentration measurements unfeasible for statistically analyzing the stability performance of these IOLs. Even so, the visual and optical differences between two groups have indirectly reflected that a plate haptic design could provide multifocal IOL models better stabilities.

Second, the material and biocompatibility of IOLs have also played important roles in IOL stability. For example, capsule contraction syndrome (including anterior capsule opacification and capsulorrhexis shrinkage) was found in 
the eyes with silicone IOLs. ${ }^{21,22}$ In addition, hydrophilic multifocal IOLs were thought to be more sensitive to postoperative decentration. ${ }^{13}$ In this study, both multifocal IOL models are produced from an ultrapure acrylate monomer that has a water content of $25 \%$. Although this material makes IOLs much elastic and malleable, it could also render IOLs "soft" haptics. Thus, the modified $\mathrm{C}$ haptic of the Acriva ${ }^{\mathrm{UD}}$ Reviol BB MF 613 would be a little "weak" to stabilize the IOL in some patients who have strong capsule contraction syndrome.

In addition, a "perfect" CCC can give IOLs 360 degree support and excellent IOL fixation. ${ }^{23}$ Compared with a manual CCC, the femtosecond laser can produce a sharp and clean-edged capsulotomy without radial nicks and tears. ${ }^{24-26}$ Meanwhile, a properly sized, shaped, and centered CCC can be precisely created by a femtosecond laser for the "ideal" IOL position. ${ }^{27-29}$ In the present study, a new femtosecond laser device (Catalys ${ }^{\mathrm{TM}}$ Precision Laser System) was used on all our cataract patients for the CCC incisions. No serious intraoperative complication (such as radial nicks and tears) occurred during these surgeries.

\section{Conclusion}

In summary, both multifocal IOL models provided excellent outcomes in distance and near visual acuities and refraction during our 6 month follow-up. Compared with the Acriva ${ }^{U D}$ Reviol BB MF 613 IOL model, the Acriva ${ }^{\text {UD }}$ Reviol BB MFM 611 IOL model has a same optic design but appeared to result in better optical performance. The plate haptic design seems to support a better stability for the diffractive multifocal IOL than the $\mathrm{C}$ haptic design. Further studies should be performed to compare their longer-term visual and optic outcomes with other plate or $\mathrm{C}$ haptic multifocal IOL models.

\section{Disclosure}

MT is a consultant for VSY Biotechnology Inc. The authors report no other conflicts of interest in this work.

\section{References}

1. Ale JB. Intraocular lens tilt and decentration: a concern for contemporary IOL designs. Nepal J Ophthalmol. 2011;3(1):68-77.

2. Knorz MC. Multifocal intraocular lenses: overview of their capabilities, limitations, and clinical benefits. J Refract Surg. 2008;24(3): 215-217.

3. Alió JL, Piñero DP, Plaza-Puche AB, Chan MJ. Visual outcomes and optical performance of a monofocal intraocular lens and a newgeneration multifocal intraocular lens. J Cataract Refract Surg. 2011; 37(2):241-250.
4. Lane SS, Morris M, Nordan L, Packer M, Tarantino N, Wallace RB 3rd. Multifocal intraocular lenses. Ophthalmol Clin North Am. 2006;19(1): 89-105.

5. Alió JL, Grabner G, Plaza-Puche AB, et al. Postoperative bilateral reading performance with 4 intraocular lens models: six-month results. J Cataract Refract Surg. 2011;37(5):842-852.

6. Can I, Bostanc1 Ceran B, Soyugelen G, Takmaz T. Comparison of clinical outcomes with 2 small-incision diffractive multifocal intraocular lenses. J Cataract Refract Surg. 2012;38(1):60-67.

7. Alió JL, Piñero DP, Plaza-Puche AB, et al. Visual and optical performance with two different diffractive multifocal intraocular lenses compared to a monofocal lens. J Refract Surg. 2011;27(8):570-581.

8. Price MO, Fairchild KM, Price FW Jr. Comparison of manual and automated endothelial cell density analysis in normal eyes and DSEK eyes. Cornea. 2013;32(5):567-573.

9. Conrad-Hengerer I, Hengerer FH, Schultz T, Dick HB. Effect of femtosecond laser fragmentation of the nucleus with different softening grid sizes on effective phaco time in cataract surgery. $J$ Cataract Refract Surg. 2012;38(11):1888-1894.

10. Buckhurst PJ, Wolffsohn JS, Naroo SA, et al. Multifocal intraocular lens differentiation using defocus curves. Invest Ophthalmol Vis Sci. 2012;53(7):3920-3926.

11. Pesudovs K. Takagi Glare Tester CGT-1000 for contrast sensitivity and glare testing in normal individuals and cataract patients. $J$ Refract Surg. 2007;23(5):492-498.

12. Hayashi K, Hayashi H, Nakao F, Hayashi F. Correlation between pupillary size and intraocular lens decentration and visual acuity of a zonal-progressive multifocal lens and a monofocal lens. Ophthalmology. 2001;108(11):2011-2017.

13. van der Linden JW, van der Meulen IJ, Mourits MP, Lapid-Gortzak R. In-the-bag decentration of a hydrophilic radially asymmetric multifocal intraocular lens secondary to capsule contraction. $J$ Cataract Refract Surg. 2013;39(4):642-644.

14. Alió JL, Plaza-Puche AB, Javaloy J, Ayala MJ, Vega-Estrada A. Clinical and optical intraocular performance of rotationally asymmetric multifocal IOL plate-haptic design versus C-loop haptic design. J Refract Surg. 2013;29(4):252-259.

15. Altmann GE, Nichamin LD, Lane SS, Pepose JS. Optical performance of 3 intraocular lens designs in the presence of decentration. J Cataract Refract Surg. 2005;31(3):574-585.

16. Baumeister M, Bühren J, Kohnen T. Tilt and decentration of spherical and aspheric intraocular lenses: effect on higher-order aberrations. J Cataract Refract Surg. 2009;35(6):1006-1012.

17. Mester U1, Sauer T, Kaymak H. Decentration and tilt of a single-piece aspheric intraocular lens compared with the lens position in young phakic eyes. J Cataract Refract Surg. 2009;35(3):485-490.

18. Crnej A, Hirnschall N, Nishi Y, et al. Impact of intraocular lens haptic design and orientation on decentration and tilt. J Cataract Refract Surg. 2011;37(10): 1768-1774.

19. Patel CK, Ormonde S, Rosen PH, Bron AJ. Postoperative intraocular lens rotation: a randomized comparison of plate and loop haptic implants. Ophthalmology. 1999;106(11):2190-2195.

20. Taketani F, Yukawa E, Ueda T, Sugie Y, Kojima M, Hara Y. Effect of tilt of 2 acrylic intraocular lenses on high-order aberrations. J Cataract Refract Surg. 2005;31(6):1182-1186.

21. Davison JA. Capsule contraction syndrome. J Cataract Refract Surg. 1993;19(5):582-589.

22. Michael K, O'Colmain U, Vallance JH, Cormack TG. Capsule contraction syndrome with haptic deformation and flexion. J Cataract Refract Surg. 2010;36(4):686-689.

23. Kránitz K, Miháltz K, Sándor GL, Takacs A, Knorz MC, Nagy ZZ. Intraocular lens tilt and decentration measured by Scheimpflug camera following manual or femtosecond laser-created continuous circular capsulotomy. J Refract Surg. 2012;28(4):259-263.

24. Palanker D, Nomoto H, Huie P, Vankov A, Chang DF. Anterior capsulotomy with a pulsed-electron avalanche knife. J Cataract Refract Surg. 2010;36(1):127-132. 
25. Priglinger SG, Haritoglou C, Palanker D, et al. Pulsed electron avalanche knife for capsulotomy in congenital and mature cataract. J Cataract Refract Surg. 2006;32(7):1085-1088.

26. Priglinger SG, Palanker D, Alge CS, et al. Pulsed electron avalanche knife: new technology for cataract surgery. Br JOphthalmol. 2007;91(7): 949-954.

27. Nagy ZZ, Kránitz K, Takacs AI, Miháltz K, Kovács I, Knorz MC. Comparison of intraocular lens decentration parameters after femtosecond and manual capsulotomies. J Refract Surg. 2011;27(8):564-569.
28. Kránitz K, Takacs A, Miháltz K, Kovács I, Knorz MC, Nagy ZZ. Femtosecond laser capsulotomy and manual continuous curvilinear capsulorrhexis parameters and their effects on intraocular lens centration. J Refract Surg. 2011;27(8):558-563.

29. Szigeti A, Kránitz K, Takacs AI, Miháltz K, Knorz MC, Nagy ZZ. Comparison of long-term visual outcome and IOL position with a single-optic accommodating IOL After 5.5- or 6.0-mm Femtosecond laser capsulotomy. J Refract Surg. 2012;28(9):609-613.
Clinical Ophthalmology

\section{Publish your work in this journal}

Clinical Ophthalmology is an international, peer-reviewed journal covering all subspecialties within ophthalmology. Key topics include: Optometry; Visual science; Pharmacology and drug therapy in eye diseases; Basic Sciences; Primary and Secondary eye care; Patient Safety and Quality of Care Improvements. This journal is indexed on

\section{Dovepress}

PubMed Central and CAS, and is the official journal of The Society of Clinical Ophthalmology (SCO). The manuscript management system is completely online and includes a very quick and fair peer-review system, which is all easy to use. Visit http://www.dovepress.com/ testimonials.php to read real quotes from published authors. 